\author{
Sabahudin Hadžialić \\ University Nicolaus Copernicus, Torun, Poland \\ e-mail: sabihadzi@umk.pl \\ UNINETTUNO University, Rome, Italy \\ e-mail: sabahudin.hadzialic@uninettunouniversity.net \\ Vilnius University, Kaunas, Lithuania \\ e-mail: sabihadzi@gmail.com
}

\title{
Theoretical aspects of media education. New technologies as the creative and innovative conditio sine qua non
}

\begin{abstract}
Understanding the media education, and education in large, in the World of XXI century is closely connected with a new technologies and advantages and disadvantages which it brings along. Sometimes, we have a serious feeling that the speed of development of the new technologies is much faster than adjusting of the media education to it. A lot of reasons are connected with that: way of communicating (how to communicate interaction of media education with new technologies) with pupils and/or students (knowledge and the skills of the youngsters and/or youth about new technologies are sometimes higher and more comprehensive than the knowledge and the skills of the teachers and professors); media (il)literacy; lack of understandings from the educational authorities (or lack of their education about it as well) about the importance of linking media education and new technologies in the post-modern world; lack of creativity by the teachers in regards adequate presentation of the importance of connecting and interacting of media education with new technologies and vice versa, although it is also connected with the motivation connected with a position of the teachers within the society - underlining the social position of
\end{abstract}


the teachers and/or professors and as well the ethical issues connected with the ways of the modules of communication; lack of innovations related to the way of linking of media education with new technologies - social media as a model of deliberative democracy within the process of media education and a lack of knowledge about the advertising the connection between media education and new technologies - the art of persuasion. This paper will show also the disadvantages of new technologies within the process of media education, especially if not used in pedagogical and didactic methodical way of the interaction of media education and new technologies to understand it as a "software" and an "hardware" of the creative and innovative world of humanity of the XXI century.

Keywords: communication, knowledge, media education, creation, innovation, new technologies, media (il)literacy, motivation, ethics, social media, advertising, pedagogy, didactics, educational authorities

\section{Introduction: Social media and education}

One of the main goals of any society is (or it should be, at least) to provide an educational system that includes a set of tools that can be utilized to ameliorate problems encountered in the social and economic world. The corresponding educational process and curriculum usually aim at targeting the knowledge and skills needed for dealing with problems throughout the world.

The rise of the digital age has opened great opportunities for people worldwide to connect with each other and access a diverse range of information. The Internet provides rich information resources which are very useful for various purposes in education, work and business as well as in keeping up with world trends. The ever-growing social media has the potential of improving the quality of instruction in education.

Some basic features of social media could have a great impact on the development of the teaching-learning process. It sought to discover the use of social media in teaching by investigating the profile of the teachers, the role of social media in education in different school activities and the acceptance of the role and use of social media in education.

Very often it is showed that social media contributes to learning but there are some disadvantages which users need to be aware of. It is 
recommended that teachers blend social media with other free learning management systems.

As much as it is useful, social media can be a huge source of distraction for students whose attention is difficult to keep sustained on school work. Most of these students end up using the internet, e-learning platforms and social media to connect with people for the sole purpose of socializing. Statistics have shown that a large percentage of people are constantly active on Social Media platforms just for the sake of socializing. Facebook, WhatsApp, Twitter, Instagram have no closing time, and it is like a merry go round - it gives access to a $24 / 7$ activity. If students are not properly monitored, they can neglect the reasons for using Social Media in Education and focus on distracting and time-wasting activities.

Post-industrial society has become more a society of services rather than a society of production. It creates new ways of human interaction with society, where artificial interfaces separate individuals from the realworld social environment. One of the trends of the previous industrial society, namely, the globalization and formalization of social institutions, and therefore, the decreasing role of the individual, has recently been replaced by personalization, placing the individual at the center of the world.

Accordingly, recently the main objectives of education have changed to reflect these tendencies. The newly conceived educational process requires changing the role of the teacher to the learner (Carolyn \& Foster, 2010; Fazal, DeSimone, \& Lieman, 2010).

Thus, the teacher is not a single content provider anymore. The learner becomes increasingly freer to collect knowledge as needed and has the power to decide.

\section{Senseless competition - Internet vs. education}

Owing to the latest achievements in information and communication technology, e.g., wireless broadband, IP, and cloud computing, the learning has become increasingly more ubiquitous, meaning that the world is adapting to the learner's mobility with no formal class distinction (Dede, 2011).

Obviously, it is senseless for the educational system to compete with the Internet and other innovative sources of educational content. On the contrary, it is much more promising to utilize this means for enhancing 
students' personal skills and abilities to improve the effectiveness of learning.

Western society, in general, and education is evolving toward personalization. This personalization is strongly connected with the new phenomenon of Personal Identity Online (PIO) that has been intensively studied in recent years (Bowman, 2009; Rodogno, 2011).

The concept of PIO personifies a specific characteristic of an individual's behavior in a network environment, which manifests itself in a unique opportunity to form the individual's identity differently from that in reality.

The world network opens new opportunities for self-expression and for forming identity. The PIO is the form of personalization that typifies post-industrial learning environments (Floridi, 2011).

Another remarkable factor characterizing the coming epoch is the phenomenon of social media. Social media are traditionally defined as the use of Web applications supporting the creation and exchange of user-generated content. Here, we should talk more about the concept of social media within more general and culturological interpretation, rather than the technological one. We consider the social media as a cultural phenomenon that should help enrichment of media literacy in whole, substantially intensifying and enhancing interpersonal communication and significantly altering the nature of the relationship between an individual and a society "personality-society".

Note that the relationships "personality-personality" and "personality-society" are immediately perceived as simple and are unprecedentedly multifaceted.

The simplicity of relationships/mutual connections is clearly seen in the availability of new communication tools (from mobile devices to social networking sites) for any level of the society, regardless of education, age, and economic status. Diversity of communication connections is a new phenomenon related, for example, to the above-mentioned phenomenon of PIO, and to the fact that an identity (a personality) in cyberspace can be perceived not only as a real person, but also as an "infosphere" directly associated with the person (Floridi, 2011).

The infosphere of an individual consists of the memory of the discussed personality/individual, the memory about the personality and multiple media documents related to the personality, lifestyle, etc. 
Infosphere of an individual somehow exists and functions in the cyberspace, independently of the corresponding personality. This has created a new media reality that, in my opinion, is the most important tool for understanding the phenomenon of social media for the education processes. In the era of social media, social consciousness is formed in accordance with new, previously unknown principles, thus establishing new goals in all spheres in education.

It is obvious that education is not an exception. In Web 2.0 and Web 3.0, the possible forms of network activity of modern students are extremely diverse. These forms include blogs and forums, social networks, wikis, etc. Thus, the above two phenomena: the social media and the personal identity online determine new forms of an educational process and new learning environments.

Thus, the above two phenomena: the social media and the personal identity online determine new forms of an educational process and new learning environments. In this way, the increased personalization is strongly connected with the increased importance of "soft" skills, such as creativity, motivation, meta-cognition, etc. (Cohen, 2009; Shute et al., 2009). In order to achieve soft skills, the development of learning environments of the new type must become a reality. Presenting of such learning environments, called Personalized Ubiquitous Educational (PUE) environments, should be considered. One of the best examples of the PUE is a cloud educational environment (Sultan, 2010; Geth, 2010). Although, we must have education authorities that will strongly support this. Or we will have a new paradigm within so call "Big brother society" where everybody thinks and act the same and nobody think and acts anything clever and, positively, pro future.

This new understanding is based on considering the PUE as a social environment and not just a technological one. I do hypothesize that the socially oriented PUE environment will provide teachers with the means to prepare a student for "multi-dimensional abilities required from them in the 21st century" (Kojukhov \& Levin, 2010; Johnson, 2010), which refers to such soft skills as creativity, motivation, meta-cognition (Cohen, 2009; Shute et al., 2009). I studied teachers' training programs oriented toward the extensive use of the personalized ubiquitous educational environment tools as a key for success and I hypothesized that integrating such tools enhances the students' acquisition of soft skills. The results 
indicate that the main principles of the Personalized Ubiquitous Educational Environment are indeed justified.

\section{Social components interaction with knowledge and vice versa}

In our post-industrial society, the social component plays the dominant role in acquiring knowledge - and this is due to several reasons:

1. A society of services is socially oriented. (Industrial society was oriented toward science and technology. Recall that medieval society was religiously, spiritually oriented).

2. The success of communication technologies. Certain devaluations of the value of knowledge favor the media. For the first time in the history of modern civilization, people may intelligently communicate, regardless of the distance and, in some sense, even regardless of time. (Hadžialić S., 2018)

3. Forms of social consciousness change, as well as the ways of forming them. Modern means of communication raise the social component of reality to an unprecedented height.

4. Personality and identity is being formed in a new way. Personality increasingly expresses itself in virtual space, which is a new international social reality. (Hadžialić S., 2016)

In pre-industrial society, the dominance of individual education was quite suitable for the structure of medieval social production. There are two types of the pre-industrial education: (1) skills-oriented practical education, meaning education of the type "do-as-I do"; (2) advanced theoretical education comprising a number of subjects, where the teacher was a highly qualified expert who taught the subject according to his/ her individual plans. Consequently, education in pre-industrial society as well as the corresponding educational environment can be characterized as personal, with direct teacher-student contact.

The bright ideas brought forth by John Amos Comenius served as the basis for education in industrial society. A class-oriented educational system was created that perfectly matched that of society, with its orientation toward the production of goods and industrial progress. One of 
the main peculiarities characterizing industrial society education is its social orientation toward formalization/standardization.

The meanings and terms of a formal curriculum, a formal class, and a formal lesson were established in the Age of Enlightenment. The classroom-lesson environment unifies and standardizes relations between teachers and students, thus, defining the social role of the teacher in society. In contrast to preindustrial society education, which is personalized education, industrial society can be characterized as having socialized education.

In contrast, post-industrial society is considered as a society of services rather than a society of production. In our opinion, post-industrial education has undergone a new process of fulfilling the role of a teacher (the teacher's authority). This is manifested by the self-educational activity of today's students having ubiquitous access to information, in which the teacher is no longer the unique content provider.

In the post-industrial school, the classic classroom-lesson system loses its usual significance. The ubiquitous manner of acquiring knowledge changes the conventional meaning and the essence of the traditional classroom. I do refer to this new type of classroom as a ubiquitous classroom. The idea of personalizing the educational process was first proposed by Seymour Papert (Papert, 1980). The idea of personalization conflicts with the conventional classroom-based educational process. Papert and his followers perceived the classroom-based system as an obstacle to social progress and as contradicting the fundamental principles of cognition (Papert, 1991).

Naturally, this brings to mind a dichotomy view in which society is divided into two portions: (1) conservative, based on a classroomoriented system, the centralized curriculum, the authoritarian teacher, the omnipotence of the Ministry of Education, and (2) progressive, having students at the center and symbolizing the rejection of centralism and based on the principle of individualism.

\section{The essence or the form?}

The new liberal school are based on the principles of constructionism (Harel and Papert, 1991; Cakir, 2008). According to these principles, the 
student builds his/her own micro-world, in which he/she implements his own cognitive abilities. In this way, the idea of decentralization and individualization has merged with the ideas of innovation), freedom, and creativity. In contrast, the old, classroom-oriented system was associated with a centralized authoritarian education that does not consider the individual student. At the same time, the idea of constructionism was fundamentally related to the use of computers in the classroom. The computer has played a revolutionary role in the constructionist approach, radically changing classroom-based education.

As seen from the above mentioned, an idea proclaimed 30 years ago returns to the forefront of educational processes and learning environments, and in fact, it serves as their principal component. Obviously, nobody speaks about returning to the Middle Ages, with their "do-as-I do" education.

One of the important points within this presentation lies in understanding the fact that such a highly individualized educational process does not correspond enough to our increasingly complex urban postindustrial society (Hadžialić S., 2016). Neglecting the social component in favor of personal component, while constituting the core idea, poses a serious problem. Developing a modern society is linked to rapid growth of communications and as a result, with unprecedented socialization of society. Under these circumstances, obviously, private individual microworlds that generated such an impressive breakthrough in the 1980s will soon be transformed into so-called social micro-worlds, though the remaining personal component. Such social micro-worlds can now be seen in the form of various social networks, blogs, Web 2.0 and Web 3.0 means, etc., which has changed the live styles not any more millions, but billions of people and has become increasingly more popular in our daily life. The relationships of our personal and social lives are rapidly changing. This, in turn, has affected education both at the level of the educational process and at the level of learning environments.

The last 30 years ushered in years of intensive computerization of society and of incredible achievements in information technology. Perhaps the idea that micro-worlds will replace classroom-based education was just an illusion. My goal is to show that this was not the case. Here, I will show that the constructionist approach successfully describes the coming post-industrial educational system, but that it needs some clarifications. 
The first clarification concerns individualization of the educational system and its resources. Modern ideas about a new educational system are based mainly on the opposite opinion (Hadžialić, 2016). Personalization is not considered to be related to individualization of computerized resources. On the contrary, the distribution of our resources turned out to be more intensive and that is why distribution increased personalization. This is especially evident in the phenomenon of "cloud" computing in education (Sultan, 2010; Geth, 2010).

The second clarification concerns the intimacy of the educational process. This position is worthy of our support. Papert noted that 30 years ago and we also see that personalization of the learning process is strongly connected with expressing and forming the learner's personal identity. Moreover, today we extend the concept by introducing Personal Identity Online (PIO) (Floridi, 2011) - an identity that a user establishes in online communications - the concept that constitutes the essence of post-industrial digital life.

As is well known, the task of forming a learner's personality is one of the main pedagogical tasks that concern today's educators. In former societies, this task was carried out by the education system. However, personality is something multi-dimensional and goes beyond its "linear" incarnation. The PIO removes personality from its default state, enabling it to appear in a new dimension.

The recent learning environments are not just customized microworlds but instead are individual micro-worlds constructed in virtual space and are interconnected with one another.

Although, the disadvantages of virtual space such as lack of privacy; being too exposed through the communication; lack of media literacy as a tool for critical thinking and observation can be avoided only with proper media education, above all.

Altogether, with the latest development in broadband wireless communications, a growing number of virtual communities are being created where a user (a student or teacher) actively behaves behind his personal identity in creating the Personal Identity Online (Ke. F. Chavez., 2011; Rodogno, 2011). Personal Identity Online is a social identity platform that a user establishes in online communities and websites. Although some people prefer to use their real names online, some internet users prefer to be anonymous, identifying themselves by means of pseudonyms that 
reveal varying degrees of personally identifiable information (Bowman, 2011; Rodogno, 2011).

In a modern world, in which the division between online and offline is being erased (Floridi, 2011), and where the online world does not respect geographical boundaries, "the self uses the digital imaginary concerning itself to construct a virtual identity through which it seeks to grasp its own personal identity (the question „who am I for you?" becomes „who am I online?"), in a potentially feedback loop of adjustments and modifications leading to an equilibrium between the off-line and the online selves" (Floridi, 2011).

Another important point related to identity is that the online identity is always present and accessible to others (Amelung, 2007). For any objects uploaded to the environment, or, for example, communications in collaborative tools, the information remains readily available and continues to influence the actions of others, even if the user is not currently on-line in the system. Users construct identities of others by knowing about and interacting with the continuously changing information provided through ongoing learning activities. Therefore, a user constructs his identity by first knowing what information he has contributed to the social context and more importantly, by knowing how others act on that information. This activity has an impact on the shared social context of a learning social community because the artifacts that personalize each user are always available and accessible (e.g. ubiquitous).

\section{Digital curration}

Teachers' meta-cognition is one of the most important personal variables that affect their engagement in modern educational environments, which include the information-seeking behaviors, the processing of information gathered in online environments, discussion forums, etc. Activities such as planning how to approach a given task, monitoring comprehension, evaluating progress toward the completion of a task, and knowledge of these activities are meta-cognitive in nature, so an important step in enhancing the education environment outcomes is to obtain clarity with regard to the influence of meta-cognition on how and how often teachers and learners bring themselves into the learning process in online forum discussions. 
As part of our main hypothesis described at the beginning of today's presentation, I do propose investigating the relationship between different components of the Personalized Ubiquitous Educational environment and participation in online discussions as well as analyzing strategy variables or factors that can influence cognition and knowledge building. One such component is Personal Identity Online. This is correlated with the content of students and teachers' participation in online discussion and hence, facilitates building collective knowledge. It is critical to design online interaction contexts to support identity presence in a manner that promotes students' meta-cognition and development of soft-skills for constructing a community collective knowledge rather than simply sharing experiences and individual insights within the presentation related to media education.

Digital curation (Higgins, 2011) is one of the most innovative and widespread kinds of network behavior. Curation a special form of blogging, in which students receive an input stream of data generated in accordance with a predefined set of keywords (tags), and then carry out their own filtering (with supervision) by selecting the messages (data), which in the student's opinion, are of interest and are "worthy" of being included in their personal "curation blog".

The result of "individual curation" is a comprehensive curation stream. This stream, in turn, has quite a personal character, because an element of the infosphere has been introduced. The curation corresponds perfectly to the present stage of social media. The streams, whose authors are both students and teachers, may freely interact, thus forming meaningful networks. The role of these networks and their dynamics in education is great. The curated streams can interact with each other. Meta-curation should be understood as management of the curated streams. In postindustrial classes, meta-curation may become one of the main activities used by the teacher. Hence, the new conditions greatly change the previous role of the teacher. The Meta-curator (teacher) directs the streams in a productive direction, in accordance with the curriculum. Actually, in a classroom, the teacher can be considered as the curator, who is the first among equals. One can imagine a variety of learning activities associated with the curated content.

In the above context, one should note that the learning activities have evolved in the classroom as follows. 
- In a traditional classroom, the process goes from observation to forming the content, then to an oral and written statement of the content. Alternatively, the process may start by remembering something, or from reading some content, and it may be followed by remembering the content and introducing it as a restatement; this process may consist of a presentation or a composition.

- In the post-industrial class, the process may be much shorter: from learning the material, web surfing, and searching, the process may comprise analysis and preservation of the content and, ultimately will lead to the curation. It is important to emphasize that the apparent superficiality of the modern educational process, in comparison with the traditional process, may be just an illusion. Perhaps we are simply not accustomed to the new reality of information that, in turn (and of course), needs to be investigated.

\section{The principles sui generis}

We can easily define the following three principles, which are applicable for education in whole as well for media educational process:

- Virtualization of reality involves transforming reality into a new context - a form of simulated reality, a new form of manifesting universal human activity by creating new knowledge, thus expanding the boundaries of objective reality. One of the major new examples of virtualized reality is that of the cloud (Satyanarayanan et al., 2009), where the educational content forms a new educational cloud paradigm (Sultan, 2010; Geth, 2010).

- Ubiquitous reality is a virtual reality (including educational content), with which the student and teachers maintains permanent communication in time and space. This permanent communication with the educational content by also adding learners' location and social context is called Ubiquitous Learning (Dede, 2011; Graf \& Kinshuk, 2008).

- Personalization is concerned with forming a personalized learning environment. This process is based on adapting to the learner's profile by using various technologies for investigating the 
specific learning history of past training activities, i.e. personal identity by using educational data mining.

The personalized ubiquitous educational environment can be characterized by the following - It comprises all the necessary components that can be formalized/computerized.

The environment may take the form of a dialog system adaptable to specific students' needs, and it is based on information about the student (educational data mining), which is strictly private and stored in his profile.

The teacher's position in the environment is radically changed in comparison with the traditional class. The teacher (the mentor) now becomes a counselor and coordinator. The teacher is also one of the developers and users of the environment, including curriculum products and tools used to evaluate the progress (rather than knowledge) of the learner.

Any educational content can be automatically synthesized and transformed to any form that is most applicable for the student, with extensive use of multimedia.

Recently society has been undergoing a period of significant changes in all aspects of life. The educational system, as one of the fundamental institutions of modern society, consequently, is strongly affected by these changes.

In analyzing forms of (1) acquiring knowledge and (2) forms of educational processes evolutions, I do claim that recently education has evolved under the strong influence of two contradictory tendencies: personalization and socialization. Personalization is manifested as a new phenomenon "Personal Identity On-line", characterizing the recent most popular activity of humans - their life in cyberspace. Socialization is manifested in the form of the phenomenon of Social Media, characterized by new forms of social relations and public awareness of a virtualized post-industrial society.

A personalization, which is manifested as a new form of Personal Identity Online and socialization, which is manifested as various forms of social media, are correct and useful concepts for studying and better understanding the educational environments of our post-industrial society. 


\section{Conclusion}

1. Post-industrial society being more a society of services rather than a society of production has a future in media education as a tool of post-modern interaction of the different kind of tools knowledge and technology that are rapidly growing, not within the days, but within the hours of our lives.

2. Social media, above all is a proper tool for the establishment not just for the exchange of information but for an exchange of educational interaction which will lead towards the better communication between students and teachers and lead towards the development of joint knowledge.

3. Being present in this post-industrial world of challenges, media education gets double advantages, comparing to the regular education:

a) We all are media within the communication, although within this post-industrial, new-age communication, we are not just media, we are the ones who creates media within the media through the ways of new communicatiom technologies such as social networks.

b) Everybody involved within the process of using of new technologies as creative and innovative conditio sine qua non and comes from media education environment is and will be a teacher of other users of social networks while being within the interaction as a student and/or teacher.

\section{References}

Amelung C. (2007), Using social context and elearner identity as a framework for an e-learning notification system, "International Journal on E-Learning", 6(4), 501-517.

Bowman S. (2009), Presence, identity, and the cloud of knowing. E-learning, politics and society, "Journal of Moray House School of Education", 1-7.

Cakir M. (2008), Constructivist approaches to learning in science and their implications for science pedagogy: A literature review, "International Journal of Environmental and Science Education”, 3(4), 193-206. 
Carolyn B. \& Foster C. (2010), Alternative certification: An effective model of online supported teacher education [in:] D. Gibson \& B. Dodge (Eds.), Society for Information Technology \& Teacher Education International Conference 2010, (pp. 17-32). Chesapeake, VA: AACE.

Cohen P. et al. (2010), Roadmap for education technology. Global Resources for Online Education, a project sponsored by the National Science Foundation and the Computing Community Consortium. Tempe, Arizona

Dede C. (2011), Emerging technologies, ubiquitous learning, and educational transformation. towards ubiquitous learning. Proceedings of 6th European Conference of Technology Enhanced Learning, EC-TEL 2011, Palermo, Italy, September 20-23, 2011.

Fazal M., DeSimone J. \& Lieman L. (2010), Involving pre-service school leaders and teachers in assessing pilot electronic portfolio implementation [in:] D. Gibson \& B. Dodge (Eds.), Proceedings of Society for Information Technology \& Teacher Education International Conference 2010, (pp. 63-65). Chesapeake, VA: AACE.

Floridi L. (2011), The informational nature of personal identity, "Minds and Machines", 21(4), 549-566. doi:10.1007/s11023-011-9259-6.

Graf S. \& Kinshuk (2008), Adaptivity and personalization in ubiquitous learning systems [in:] A. Holzinger (Ed.), USAB, LNCS 5298, (pp. 331-338). Berlin, Germany: Springer-Verlag.

Hadžialić S. (2018), Social media and social innovation. Proceedings paper of the XIII International Scientific On-line Conference „Knowledge-Media-Education“, Nicolaus Copernicus University, Torun, Poland, Jun 2017 published in May 2018 in "Cognitive science - New media - Education" - reviewed, e-journal (Vol 2, No1, 2017, Pages. 33-56, ISSN: 2543-506X, May 2018)

Hadžialić S (2017), Paper: "Demagogy of the media: information or manipulation", an International Journal of Ideas - Approved Journal in Social Sciences, Published by Babuddin Khan, New Delhi, India, ISSN 0970 7247, Volume 31, No 370, July 2016, Pages 22-29 (I part).

Hadžialić S. (2016), Paper: "Transformation of the New Communication Media within the Frame of Interpersonal Interaction", International Journal on Global Business Management and Research, a Bi_Annual Journal published by Rajalakhsmi Institutions, Tamilnadu, India, ISSN 2278 8425, Volume 5, Issue 2, August 2016, Pages 116-134.

Hadžialić S. (2016), Paper: "Perspectives on social media and Social innovations", an International Journal of Ideas - Approved Journal in Social Sciences, 
Published by Babuddin Khan, New Delhi, India, ISSN 0970 7247, Volume 30, No 353, July 2016, Pages 23-27.

Harel I. \& Papert S. (1991), Constructionism, Ablex Publishing.

Ke F., Chávez, A. F., Causarano P.-N. L. \& Causarano, A. (2011), Identity presence and knowledge building: Joint emergence in online learning environments?, "International Journal of Computer-Supported Collaborative Learning", 6(3), 349-370. doi:10.1007/s11412-011-9114-z

Papert S. (1980), Mindstorms: Children, computers, and powerful ideas, New York, NY: Basic Books.

Rodogno, R. (2011), Personal identity online, "Special Issue in Journal of Philosophy \& Technology", 24. Netherlands: Springer.

Satyanarayanan M., Bahl P., Caceres R. \& Davies N. (2009), The case for VMbased cloudlets in mobile computing, "Pervasive Computing", 8(4), 14-22. doi:10.1109/MPRV.2009.82

Shute V. J., Zapata D., Kuntz D., Levy R., Baker R., Beck, J. \& Christopher R. (2009), Assessment: A vision. Global Resources for Online Education, a project sponsored by the National Science Foundation and the Computing Community Consortium, Tempe, Arizona

Sultan N. (2010), Cloud computing for education: A new dawn?, "International Journal of Information Management”, 30, 109-116. doi:10.1016/j. ijinfomgt.2009.09.004

\section{Internet sources}

Sadler J. E., John Amos Comenius, Encyclopædia Britannica, https://www.britannica.com/biography/John-Amos-Comenius (access date: 10.5.2019).

Hadžialić S., Social media for summer semester 2018/2019, https://www.youtube.com/watch?v=cFOnMeJAs0c (access date: 11.5.2019).

Hadžialić S., Sabahudin Hadzialic - teaching session in Czernikowo, Poland, 27.3.2019, https://www.youtube.com/watch?v=ttaRs28NN7U (access date: 11.5.2019). 